\title{
A New Procedure for Diatom Extraction in the Diagnosis of Drowning
}

\section{Nadia Fucci*}

Forensic Laboratory-Institute of Legal Medicine, Catholic University of Rome, Italy

\begin{abstract}
A simple and economical procedure for the destruction of human organic material for the diatom examination is presented.

The Author has tested a minimal amount of $\mathrm{H}_{2} \mathrm{SO}_{4}$ diluted solution to detect diatoms in several tissues from human corpses under crime investigation, immersed in the sea and river water.

The method was compared with a traditional method that includes digestion with a large amount of strong mixture of sulphuric and nitric acid (90\%).

The new procedure showed that all siliceous frustules of sea and river diatoms are more resistant to the $\mathrm{H}_{2} \mathrm{SO}_{4}$ diluted treatment and are still recognizable after digestion, and observation under the micrscope is better than the other procedure.
\end{abstract}

Moreover, the microscopical observation of amoeboid protozoa (radiolarians) was also possible.

Keywords: Diatom; Radiolarians; Rowing; Sulphuric extraction

\section{Introduction}

Diatoms are unicellular, eukaryotic microorganism measuring from 5 micron to $3 \mathrm{~mm}$. They appeared in the prehistoric era, colonize all aquatic or simply moist environments and can also be found in dust.

The first observation of diatom was made in 1703 by an english country gentleman with a simple microscope. His paper was communicated to the Royal Society of London and published in its Philosophical Transaction [1].

The hallmark of the diatom is its cell wall is highly differentiated and almost always heavily impregnated with silica. There are two principal habitats for diatoms: moist or submerged surface (Benthic) and open water (Planktonic).

In forensic science a fairly important and difficult issue is the diagnosis of drowning in the case of submerged corpses specially when a corpse is heavy putrid or decomposed. The "diatom test" is based on the recovery of the siliceous cell wall diatoms in high concentration in the organs of drowned persons because diatoms pass through the alveoli into the great circulation. A great number of tests have been proposed to support a confirmation or exclusion of drowning [29]. In the case of corpse putrefaction the diagnosis of drowning is rather difficult, for this purpose the diatom analysis could provide supplementary evidence.

Limits affecting diatom testing usually arise from the specific type of analysis; identification of diatoms generally follows a digestion of tissues by strong acids: this treatment may destroy diatoms with the risk of a false negative [10]. On the other hand, the use of other methods such as enzymatic digestion with proteinase $\mathrm{K}$ are very uneconomical and not for the exhaustive extraction of some species of diatoms [1112].

In this paper a comparative analysis was performed: in the first procedure (classic method) the extraction with strong acids (sulphuric and nitric acid digestion at $90^{\circ} \mathrm{C}$ ); in the second only the addition of $\mathrm{H}_{2} \mathrm{SO}_{4}$ diluted $30 \%$ with a small amount of organic matter, maintaining overnight at room temperature.

Two digestion procedures were applied to a total of ten cases of drowning in rivers and the sea. Only for two cases the examination of the drowning medium (water and sediment) was possible.

\section{Sample}

The analytical procedures were performed on ten dead bodies under crime investigation at the Forensic Toxicology laboratory of the Institute of Legal Medicine on behalf of the judiciary. They were eight cases of bodies found in the river and two found in the sea.The bodies had been found many days after their disappearance. At the beginning of the autopsy an aliquot of different organs (liver, lung, kidney, brain) was taken and transferred to the forensic laboratory. Moreover the drowning medium was available for only two cases; the water and sediment was taken on the seabed where the dead bodies had been found.

\section{Materials and Method}

One gram of kidney, liver, lung and brain were taken and placed in glass baker containing an equal amount of a mixture of strong sulphuric and nitric acid and placed at $90^{\circ} \mathrm{C}$ overnight. For the other procedure ten milliliters of $\mathrm{H}_{2} \mathrm{SO}_{4}$ diluted at $30 \%$ at room temperature overnight was added to dissolve the organic matter. A negative control was also performed (sample taken by a dead body for other cause) on both extraction procedures. An aliquot of distilled water added to all the samples. Then the extracted samples were centrifuged at $4000 \mathrm{rpm}$, and the supernatant removed twice. After sedimentation a quantity of 100 microliter for each sample was collected, spread on a slide and dried in an oven at $90^{\circ} \mathrm{C}$. Slides obtained from all extracted organs were analyzed with light microscope. The diatoms were identified according to "The diatoms biology and morphology of the genera" [1].

*Corresponding author: Nadia Fucci, Forensic Laboratory-Institute of Legal Medicine, Catholic University of Rome, Italy, E-mail: nadiafucci@rm.unicatt.it

Received March 16, 2012; Accepted April 28, 2012; Published April 30, 2012

Citation: Fucci N (2012) A New Procedure for Diatom Extraction in the Diagnosis of Drowning. Clin Exp Pharmacol 2:110. doi:10.4172/2161-1459.1000110

Copyright: (c) 2012 Fucci N. This is an open-access article distributed under the terms of the Creative Commons Attribution License, which permits unrestricted use, distribution, and reproduction in any medium, provided the original author and source are credited. 
Citation: Fucci N (2012) A New Procedure for Diatom Extraction in the Diagnosis of Drowning. Clin Exp Pharmacol 2:110. doi:10.4172/21611459.1000110

\section{Results}

The digestion performed with the classic method appeared to be very aggressive with a high presence of destroyed diatom fragments. On the contrary, the other digestion procedure is less aggressive and no presence of precipitates was observed.

Diatoms taxa present in the digestion tissues were: Fragilaria and Navicula. The presence of Asterionella was revealed only in the drawing medium. In Table 1 the diatoms identified in different tissues samples are summarized employing the two different extraction procedures.

The genera identified came from the acquatic environment, navicula, fragilaria and asterionella which are typical diatoms that can be found in marine and river environments. In addition to the diatoms in the organ extracts were detected in the presence of abundant radiolarians [13] amoeboid protozoa. There are characterized by a siliceous skeleton with spicules arranged in rays that observed under a microscope give them a starry look. Their structure consists of numerous fine needles that emanate radially from the core. They are destroyed easily and in fact any manipulation of the fragments (formed by needle-like structures) is clearly visible to microscopes. These organisms are part of the marine plankton, can be detected at all depths and are found on the sea surface in abyssal areas, both near the coast and offshore but are most abundant at depths not exceeding a few hundred meters. As regards the two cases of drowning, where the drowning medium was available, the presence of the same taxa as those identified in the tissues was revealed. Moreover the number of distinctive types of diatoms in the drowning medium greatly exceeded in the number of species in the tissues samples. In fact, the presence of asterionella was not shown in the tissues extracted with both extraction procedures.

In Figure 1,2,3,4 all the types of microorganisms identified are shown, respectively navicula, fragilaria, asterionella, radiolarians. According to literature data $[14,15]$ to assess the diagnosis of drowning, the analysis was considered positive when the presence of 20 diatoms was identified in each 100 microliter slide of a pellet obtained from

\begin{tabular}{|c|c|c|}
\hline \multirow[t]{2}{*}{ CASES STUDIED } & DIATOMS IDENTIFIED & \\
\hline & CLASSIC METHOD & NEW METHOD \\
\hline \multirow[t]{11}{*}{$\begin{array}{l}\text { EIGHT CORPSES } \\
\text { IMMERSED IN THE } \\
\text { RIVER }\end{array}$} & $\begin{array}{l}\text { LIVER: Navicula ( } 8 \text { cases)- } \\
\text { Fragment of exoskeleton ( } 6 \\
\text { cases) }\end{array}$ & Navicula ( 9 cases) \\
\hline & & Fragilaria ( 6 cases) \\
\hline & & Radiolarians ( 6 cases) \\
\hline & $\begin{array}{l}\text { LUNG: Navicula ( } 6 \text { cases)- } \\
\text { Fragment of esoskeleton ( } 8 \\
\text { cases) }\end{array}$ & Navicula (8 cases) \\
\hline & & Fragilaria ( 5 cases) \\
\hline & & Radiolarians ( 6 cases) \\
\hline & $\begin{array}{l}\text { KIDNEY: Navicula ( } \\
5 \text { cases)-Fragment of } \\
\text { esoskeleton ( } 8 \text { cases) }\end{array}$ & Navicula ( 6 cases) \\
\hline & & Rariolarians ( 4 cases) \\
\hline & $\begin{array}{l}\text { BRAIN: fragment of } \\
\text { esoskeleton ( } 10 \text { cases) }\end{array}$ & Navicula (6 cases) \\
\hline & & Fragilaria ( 5 cases) \\
\hline & & Radiolarians 4 cases) \\
\hline $\begin{array}{l}\text { DROWING } \\
\text { MEDIUM ( } 2 \text { cases) }\end{array}$ & Navicula- Fragilaria & $\begin{array}{l}\text { Navicula-Fragilaria- } \\
\text { Asterionella-Radiolarians }\end{array}$ \\
\hline
\end{tabular}

Table 1: Diatoms identified in different tissues samples employing the two different extraction procedures.

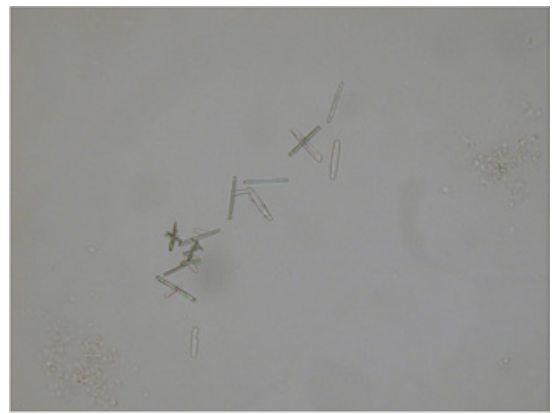

Figure 1: Diatom species of the Navicula observed under the optical microscope (analytical condition in the text).

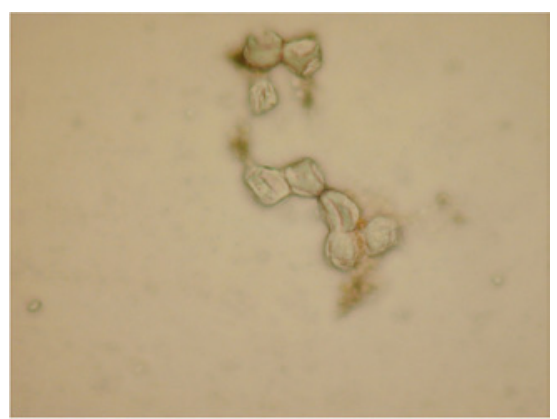

Figure 2: Diatom species of the Fragilaria observed under the optical microscope.

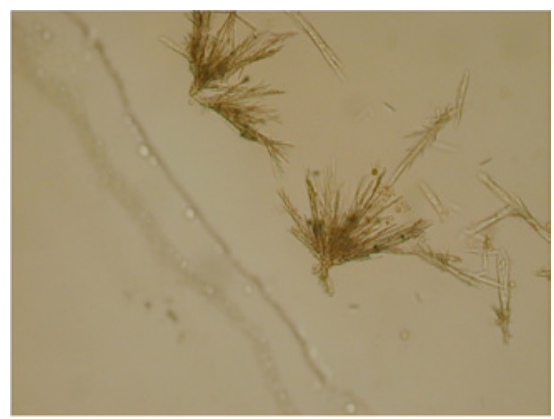

Figure 3: Diatom species of Asterionella observed under the optical microscope.

one gram of kidney, lung, liver and brain. No false positive results were observed for the cases of death from other causes. In the ten cases examined the diatom analysis gave positive results supporting the hypothesis of drowning.

\section{Discussion}

The diatom test is based on the inhalation of microorganisms suspended in the fluid medium in the process of drowning. Diatoms can enter the ruptured pulmonary alveolar and capillaries, and reach the organs in the greater circulation [16]. Postmortem extraction and detection of diatoms are possible because their silica-based-extracellular coat or frustules are resistant to different digestive reagents. However the problem is to have an extraction system that is not too aggressive and will not destroy the siliceous material, but that will ensure the complete extraction of these algae from the human organs. 
Citation: Fucci N (2012) A New Procedure for Diatom Extraction in the Diagnosis of Drowning. Clin Exp Pharmacol 2:110. doi:10.4172/21611459.1000110

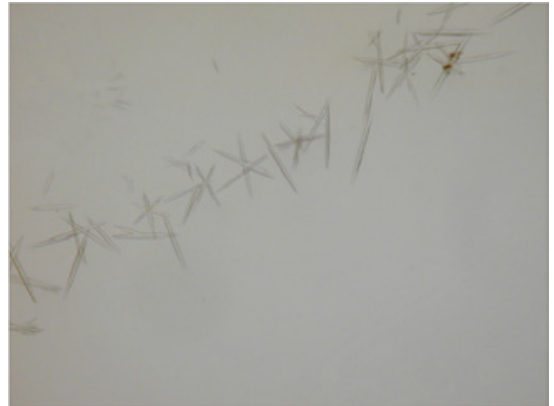

Figure 4: Amoeboid protozoa species of radiolarian observed under the optical microscope.

The system employed in this study of diluted $\mathrm{H}_{2} \mathrm{SO}_{4}$ showed better results than the classical method with sulphuric acid and nitric acid at high concentration. The classic extraction caused aggressive digestion with a decrease of diatoms and high presence of destroyed diatom fragments. Moreover, the proposed procedure is less chemically hazardous for the operator and the laboratory, it is also cheaper and yields more reliable results than those for the enzyme [11,12]. The advantage over technique proposed in the literature is that it is also possible to use a small amount of organ and small volume of already diluted acid without increasing sediment and avoiding the consequent difficulties observed in microscopic analysis. Another advantage of the proposed procedure is the possibility to observe other microorganisms (radiolarians) in human organs supporting the diagnosis of drowning. However even if several methods have been presented in the scientific literature, in accordance with other Authors [17] I think that the main problem is a lack of a standardized method for both digestion and for viewing under the microscope as well as the evaluation of a positive result. The real problem in this context is a lack of operational protocols, including the collection of drowning medium every time a corpse is found submerged in water with a suspicious death of drowning, therefore guidelines are desirable.

\section{References}

1. Round FE, Crawford RM, Mann DG (1992) The diatoms biology and morphology of the genera. Cambridge University Press.
2. Funayama M, Aoki Y, Sebetan IM, Sagisaka K (1987) Detection of diatoms in blood by a combination of membrane filtering and chemical digestion. Forensic Sci Int 34: 175-182.

3. Ming M, Meng X, Wang E (2007) Evaluation of four digestive methods for extracting diatoms. Forensic Sci Int 170: 29-34.

4. Lorente JA, Hernandez-Cueto C, Villanueva E, Luna JD (1990) The usefulness of lung surfactant phospholipids in the diagnosis of drowning. J Forensic Sci 35: $1367-1372$.

5. Yoshimura S, Yoshida Y, Okii T, Tokiyasu T, Watabiki T, et al. (1995) Detection of green algae (Clorophyceae) for the diagnosis of drowning. Int $\mathrm{J}$ Legal Med 108: 39-42.

6. Qu J, Wang E (1992) A study on the diagnosis of drowning by examination of lung chlorophyll (a) of plantons with spectrofluorophotometer. Forensic Sci Int 53: 149-155.

7. Betz P, Nerlich A, Penning R, Eisenmenger W (1993) Alveolar macrophages and the diagnosis of drowning. Forensic Sci Int 62: 217-224.

8. Yange L, Chuanying H, Chengxing W, Xu W (1999) Development of can fo destruction of organic material in use for forensic diatom examination. Forensic Sci Int 101: 163-166

9. Sidari L, Di Nunno N, Costantinides F, Melato M (1999) Diatom test with Soluene-350 to diagnose drowning in sea water. Forensic Sci Int 103: 61-65.

10. Azparren JE, Vallejo G, Reyes E, Herranz A, Sancho M (1998) Study of the diagnostic value of strontium, chloride, haemoglobin and diatoms in immersion cases. Forensic Sci Int 91: 123-132.

11. Ludes B, Quantin S, Coste M, Mangin P (1994) Application of a simple enzymatic digestion method for diatom detection in the diagnosis of drowning in putrified corpses by diatom analysis. Int J Legal Med 107: 37-41.

12. Takeichi T, Kitamura $O$ (2009) Detection of diatom in formalin-fixed tissue by proteinase K digestion. Forensic Sci Int 190: 19-23.

13. Anderson, Roger O (1983) Radiolaria. New York: Springer-Verlag.

14. Ludes B, Coste M, North N, Doray S, Tracqui A, et al. (1999) Diatom analysis in victim's tissues as an indicator of the site of drowing. Int $\mathrm{J}$ Legal Med 112 163-166.

15. DiGiancamillo A, Domeneghini C, Gibelli D, Cattaneo C (2011) Diatom extraction with $\mathrm{HCl}$ from animal tissues: a technical note. Leg Med 13: 268-271.

16. Lunetta P, Penttila A, Hallfors G (1998) Scanning and transmission electron microscopical evidence of the capacity of diatoms to penetrate the alveolocapillary barrier in drowning. Int J Legal Med 111: 229-237.

17. Hurlimann J, Feer P, Elber F, Niederberger K, Dirnhofer R, et al. (2000) Diatom detection in the diagnosis of death by drowning. Int $\mathrm{J}$ Legal Med 114: 6-14. 